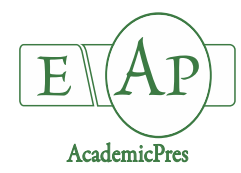

Hysa A and Teqja Z (2020)

Notulae Botanicae Horti Agrobotanici Cluj-Napoca 48(3):1667-1682

DOI: $10.15835 /$ nbha48311994

Research Article

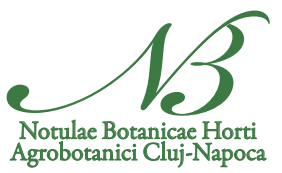

\title{
Counting fuel properties as input in the wildfire spreading capacities of vegetated surfaces: case of Albania
}

\author{
Artan $\mathrm{HYSA}^{1 *}$, Zydi TEQJA ${ }^{2}$ \\ ${ }^{1}$ Epoka University, Faculty of Architecture and Engineering, Tirana, Albania; ahysa@epoka.edu.al (*corresponding author) \\ ${ }^{2}$ Agricultural University of Tirana, Faculty of Agriculture and Environment, Tirana, Albania; zteqja@ubt.edu.al
}

\begin{abstract}
Extreme weather conditions characterized by increased peak temperatures and stretched draught seasons are expected to boost up wildfire vulnerability in Mediterranean countries such as Albania. Thus, estimations about wildfire spread capacities of the territory are crucial. In this paper we introduce four new parameters into the indexing method for classifying the forested lands by their wildfire spreading capacity (WSCI). Land cover type via Corine Land Cover (CLC), Plant heat zones, Tree cover density (TCD), and Normalized difference vegetation index (NDVI) are integrated along with the previous set of criteria. The analytical steps of the process are performed in QGIS software including the Semi-Automatic Classification Plugin (SCP) which is useful in calculating NDVI values. The diversity among the inventory values of the selected criteria urges for a normalizing procedure within QGIS. Besides, each criterion is foreseen to have a specific impact on the WSCI value, which is weighted via Analytic Hierarchy Process (AHP). The sum of the products of the normalized class and the weighted impact factor of each criterion generates the WSCI value. The validation relies on the comparison between the index values of points being located within the burned areas and the values of the remaining locations. The results have shown that the former set of points have higher WSCI mean value then the latter group of points. Lastly, the parametric vulnerability assessment method presented here enables useful materials in support of wildfire risk reduction within the national priorities of disaster risk management and fire safety agendas in Albania.
\end{abstract}

Keywords: analytic hierarchy process; disaster risk reduction; NDVI; QGIS; wildfire

\section{Introduction}

Even though wildfires have been a natural phenomenon on earth during the last 350-400 million years (Scott, 2000; He et al., 2016), the land use changes of anthropogenic origin have caused an increased fire risk to the society in social as well as economical means. The occurring processes of climate change and global warming will boost further the chances for wildfire events soon (Liu et al., 2010). In Europe, the future scenarios highlight a remarkable extension of the high risky areas from the Mediterranean region towards the northern parts. Based on the future projections, not only the northern Europe will start to struggle with hardly to manage wildfire events, but also the wildfire season in the southern Europe will be stretched in time (Moriondo et al., 2006). Unmanageable forest fire events, such as the Swedish wildfires during the summer of 2018, are expected to become more frequent.

Received: 07 Jul 2020. Received in revised form: 06 Sep 2020. Accepted: 10 Sep 2020. Published online: 14 Sep 2020. 
As if the recent global emergencies regarding the changes in the wildfire regimes were not enough, fundamentally, wildfire phenomenon has been accepted as a wicked problem (Chapin et al., 2008). It has a multi-layered character implicating a variety of cause-effect cycles operating in a certain study area (Levin et al., 2016). Besides the environmental factors, a significant implication level is reserved to anthropogenic drivers in the territory (Kulig and Botey, 2016). Therefore, some scholars have depicted wildfire as a "socioecological pathology" (Fischer et al., 2016).

Besides the dichotomy among wildfire causes into natural and anthropogenic character, we follow a further division which is related to the process of wildfire behaviour. The current literature defines a clear separation between the ignition and spreading phases of a wildfire event (Cardille et al., 2001). This split of wildfire occurrence and expansion processes brings a necessity for sub setting the driving factors respectively for each phase (Turco et al., 2014). In this study we focus on the spreading phase of the wildfire, aiming an enhanced comprehensiveness level in considering the relevant factors.

In this context, there is a need for updated informative tools and methods to better understand the wildfire phenomena under these emerging circumstances. This becomes more crucial for under-developed and developing countries where geospatial data on historical trends of wildfire ignition and spread regimes are missing. This study aims to improve a cost-free and automized method for classifying the vegetated surfaces by their wildfire spreading capacities. Initially, it follows the framework developed by Hysa and Baskaya (2019), who proposed a GIS-based method for indexing the broadleaved forests by their wildfire ignition probability index (WIPI) and wildfire spread capacity index (WSCI). Furthermore, the method is tested at metropolitan scale focusing on the wildfire risk within the wildland urban interfaces (WUI) (Hysa, 2019). The original method stands on multi-criteria of social, environmental, and physical character, concluding that the addition of fuel properties will have remarkable effect on the reliability of the model and should be included in future studies.

Consequently, in this study we bring fuel properties as the fourth category of criteria that has a direct impact on the spreading phenomenon of wildfires. Vegetation type, Plant Heat Zones map, Tree cover density (TCD) and normalized difference vegetation index (NDVI) are introduced as new criteria providing quantifiable information about fuel properties. Figure 3 represents four sets of criteria shortlisted of having direct implication with wildfire spreading behavior. Geospatial information about each criterion is acquired via a variety of sources. At this stage we bring the case of the Albanian territory as study area since the plant heat zone map was already accessible (Teqja et al., 2018). Further detail about materials and the data sources will be delivered in the second section of this paper.

The method proposed in this study is reproducible to other case studies, especially the developing countries where the historical geospatial evidences are missing. Yet, certain drawbacks related with the validity of the method are discussed and targeted as further improvements and future steps of the research. Finally, since the results stand on the landscape scale, they are useful as a reference material in support to wildfire prevention and management agendas in both national and regional levels.

\section{Materials and Methods}

\section{Studyarea}

Albania is a small country located in south-eastern Europe and has a total area of $28,748 \mathrm{~km}^{2}$ (Figure 1). The natural landscapes are characterized by a typological variety due to the diverse topography, climate, and natural resources. Albania is mainly a mountainous geography consisting; $28 \%$ of mountains, $47 \%$ of hills, and $25 \%$ of plain areas not exceeding $300 \mathrm{~m}$ above sea level. The average altitude of the topography is $708 \mathrm{~m}$, doubling the average altitude of Europe (Mullaj et al., 2017). The terrain is very complex with alluvial valleys meandering through coastal hills and mountains. The Albanian pedological landscape is very diverse and 
complex. The lower coastal area of the western part of the country is mainly formed by the fluvial activity of several rivers flowing to the Adriatic and Ionian Seas (Zdruli, 2005).

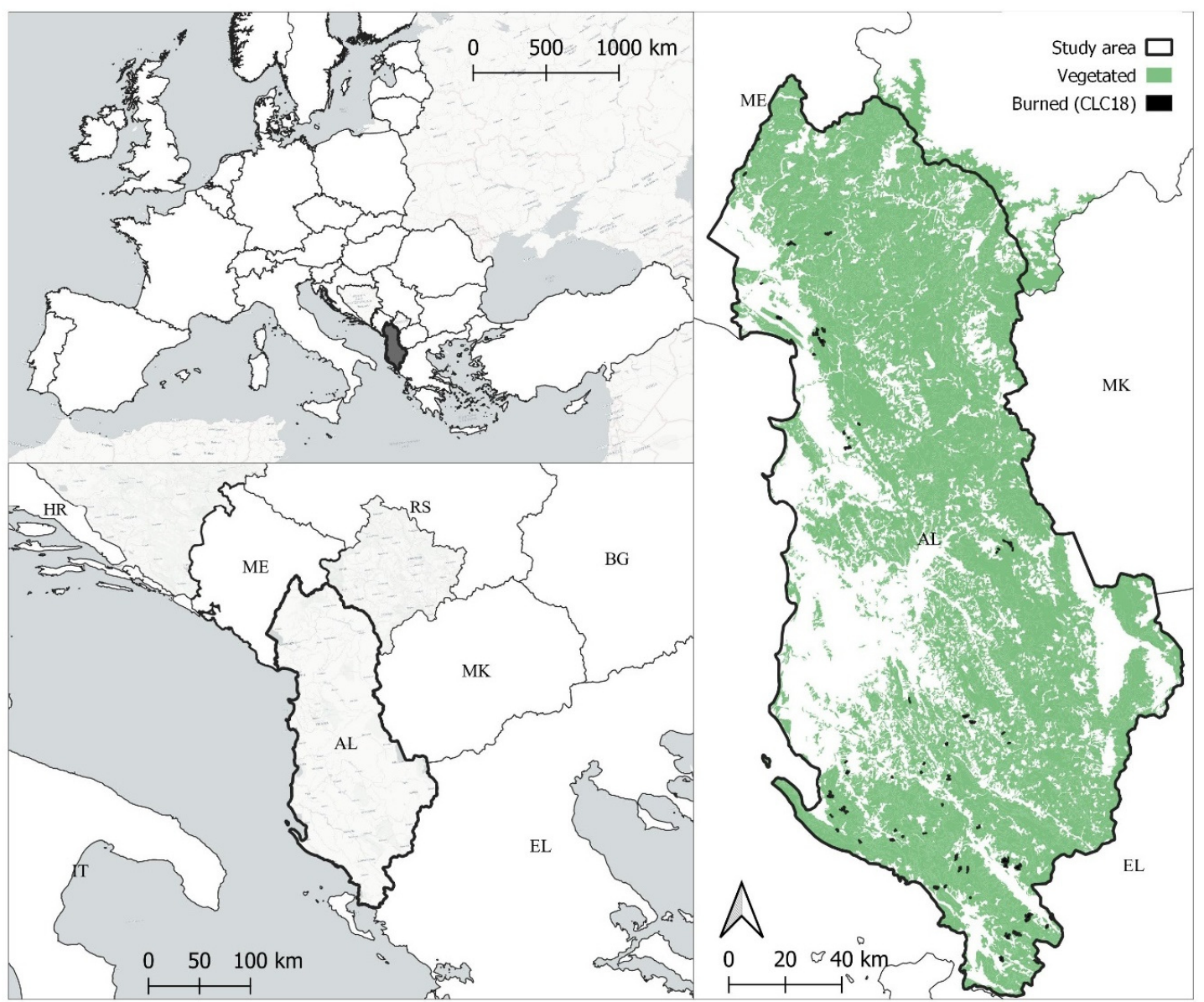

Figure 1. The study area consisting of the territory of the Albanian Republic within the European continent, including the vegetated areas and the burned surfaces as reported in CLC data of 2018

Regarding the climate conditions the territory of Albania belongs to the subtropical sub belt of western coasts which is divided into two climatic zones: the Atlantic Mediterranean zone and the continental zone. Because of mountainous, high-relief terrain the climate varies within short distances. So, the microclimatic effects created over the Albanian territory make the climate very diversified. The western coastal area is relatively flat and is dominated by a Mediterranean climate, with mild winters and hot summers. In this area, the mean winter temperature is about $7{ }^{\circ} \mathrm{C}$ and the mean summer temperature is about $24^{\circ} \mathrm{C}$ but can go to more than $30^{\circ} \mathrm{C}$, especially in the south-western part.

The mountainous areas, which comprise close to two-thirds of the territory, are influenced by a more continental climate. Precipitation varies greatly between regions. The mean annual precipitation for the coastal areas ranges from 1000 to $1500 \mathrm{~mm}$ and falls mostly during fall and winter. The mountainous areas, especially Albanian Alps, can receive as much as $2500 \mathrm{~mm}$ of precipitation, with $20-30 \%$ of it in the form of snow (Jaho and Mici, 1988). Currently, most of the territory is under plant hardiness zones 8 and 9 and plant heat zones 4-5 (Teqja et al., 2017). But significant shifts have been projected under different climate change scenarios which potentially lead to an increase in wildfire risk (Teqja et al., 2018). All these geophysical and climacteric facts make the Albanian territory highly vulnerable to wildfire risk and a relevant case to be further investigated within the scope of this study. 


\section{The multi-criteria framework and the workflow of the method}

The workflow of the method is organized in five main stages and nine steps in total as represented in Table 1. First, the initial stage consists of the definition of the study area and the reference points that fall within the vegetated surface geometries. The reference points are extracted from a regular points grid of $500 \mathrm{~m}$ distance. Consequently, each point represents a surface area of 25 ha coinciding with the MMU of CLC data (Büttner, 2014). They will serve as pivot points being loaded with the measurements and indexed values in the further steps of the process.

Table 1. The Workflow of the process for calculating WSCI values in QGIS

\begin{tabular}{|c|c|c|c|c|}
\hline & Stage & & Objective & Method/ tool/ command \\
\hline \multirow[t]{3}{*}{$\mathrm{I}$} & Initial & 1 & Defining the Study Area & Extracting vegetated surfaces from CLC data \\
\hline & & 2 & $\begin{array}{l}\text { Generating regular points } \\
\text { grid }\end{array}$ & Vector/ Research tools/ Regular points ( $500 \mathrm{~m})$ \\
\hline & & 3 & Generate reference points & $\begin{array}{l}\text { Extracting the points overlapping with vegetated } \\
\text { surfaces }\end{array}$ \\
\hline \multirow[t]{2}{*}{ II } & Inventory & 4 & $\begin{array}{c}\text { Measuring raw values for each } \\
\text { criteria }\end{array}$ & $\begin{array}{l}\text { "Sample Raster Value" tool for raster data and } \\
\text { "Distance to Nearest Hub" for vector layers. }\end{array}$ \\
\hline & & 5 & Multi-criteria inventory & $\begin{array}{l}\text { Projecting/converting individual values into raster } \\
\text { layer. Aggregating them into the reference points layer } \\
\text { via "Sample Raster Value" tool. }\end{array}$ \\
\hline \multirow[t]{2}{*}{ III } & Refinement & 6 & Normalizing & $\begin{array}{l}\text { Normalizing the raw values of each criteria spread into } \\
\text { the range of values between } 0 \text { and } 1 .\end{array}$ \\
\hline & & 7 & Defining weighting factors & $\begin{array}{l}\text { Assign weight to each criteria based on Analytical } \\
\text { Hierarchy Process (AHP, pairwise comparison). }\end{array}$ \\
\hline IV & Indexing & 8 & Calculating WSCI & $\begin{array}{l}\text { Field calculator: the total sum of products between the } \\
\text { weighted factor and the normalized inventory value of } \\
\text { each criterion. }\end{array}$ \\
\hline $\mathrm{V}$ & Validation & 9 & $\begin{array}{l}\text { Cross-check with burned } \\
\text { areas }\end{array}$ & $\begin{array}{c}\text { Evaluate the results of the points that fall within the } \\
\text { burned areas in comparison with other reference } \\
\text { points. (Scatter plot) }\end{array}$ \\
\hline
\end{tabular}

Referring to Table 1 the second stage of the workflow is the inventory of raw measurements for each criterion. This phase is based on a multi-criteria inventory method developed by Hysa et al. (2017) for analysing the burned surfaces within a specific study area at landscape scale. This step results in an aggregate attributes table of the reference points layer, which consists of 15 columns, one per each criterion represented in Figure 2. Yet, these values are of different units and range gradient. Thus, we have utilized the Min-max normalizing technique to reclassify each set of values per each criterion into a range gradient between 0 and 1 (Eq. 1). Minmax normalization is accepted the simplest and the most suitable for cases where the bounds of a range of values are recognizable (Jain et al., 2005).

$$
\mathrm{x}^{\prime}=\mathrm{x}-\min (\mathrm{X}) / \max (\mathrm{X})-\min (\mathrm{X})
$$

Besides normalizing procedure, another crucial step of the refinement stage is the assignment of weighted impact factors for each criterion. While, the wildfire spreading capacity relies on an extensive range of factors as we bring here, they do not contribute equally. Thus, we bring a weighting procedure among them relying on Analytical Hierarchy Process (AHP). We have utilized a semi-automatic procedure of pairwise comparison as developed by Goepel (2018). First, there have been assigned weighted values to four main criteria categories (social, environmental, physical, and fuel). Then, the criteria within each category are weighted their specific factors. As shown in Table 4, the final impact factor for each criterion is defined as a product between the category factor and the specific one calculated within the category. 
The indexing stage consist of a field calculator step utilizing the WSCI equation (Eq. 3). It is calculated via field calculator as the total sum of products between the weighted factor and the normalized inventory value of each criterion. Here we open for discussion a validation procedure which is integrated as the last stage of the workflow. The validation procedure relies on a comparative analysis between the WSCI results of points that fall within the already burned surfaces and the WSCI values of the remaining other reference points.

\section{Materials and data acquisition}

This research relies on a variety of geospatial data. We have targeted the utility of open source data in order to maximize the reproducibility of the method in other regions. The materials have been selected according to the geospatial information needs of the shortlisted criteria of social, environmental, geophysical and fuel background. According to Figure 2, CLC data is utilized for extracting the vegetated areas, which defines the core study area within the national borders. Furthermore, CLC evidences are used for defining the geospatial features of urbanized areas (S1), agriculture (S5), water surfaces (P4), as well as the fuel type in reference to flammability (F1).

The environmental and hydrometeorological data are derived from WorldClim (version 2.1). Here we have used the monthly average data of temporal period between 1970 and 2000, being available as raster data at a spatial resolution of 30 seconds (Fick and Hijmans, 2017). The climacteric data provides geospatial information for the following environmental criteria; solar radiation (E1), precipitation (E2), maximum temperature (E3), and wind speed (E4). Digital Elevation Model (EU-DEM v1.1) provided by EEA at $25 \mathrm{~m}$ resolution is used to feed the process with reliable information about slope (P1), aspect (P2), and elevation (P3). While other criteria such as distance to any road (S3), distance to main roads (S4) rely on Open Street Map (OSM) data.

The above-mentioned data sources have been utilized in our previous studies in support of social, environmental, and physical criteria. While, in this study we introduce four criteria related with the fuel properties which rely on three new data sources. CLC remains the main raw material to provide information about fuel type for further reclassification based on relative flammability factor. Plant Heat Zone map provides divisions of the territory based on annual temperature extremes and the plant relative resistance.

Tree cover density is proposed as an evidence of fuel quantity in relation to wildfire spreading capacities. Finally, Normalized difference vegetation index (NDVI) is promoted as a criterion which identifies the dryness level of vegetation with a direct correlation to the flammability of the fuel. The following subsections include further details about the relevancy of new criteria to the wildfire spreading capacity as well as their acquisition.

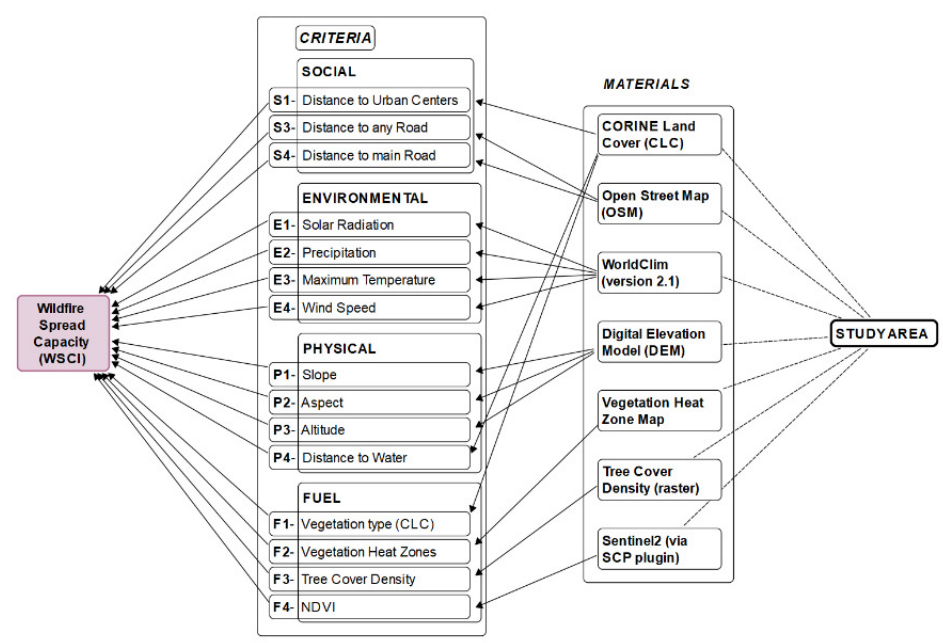

Figure 2. The multi-criteria model for WSCI indexing based on social, environmental, physical and fuel properties of the vegetated locations, including the respective raw materials and data sources 

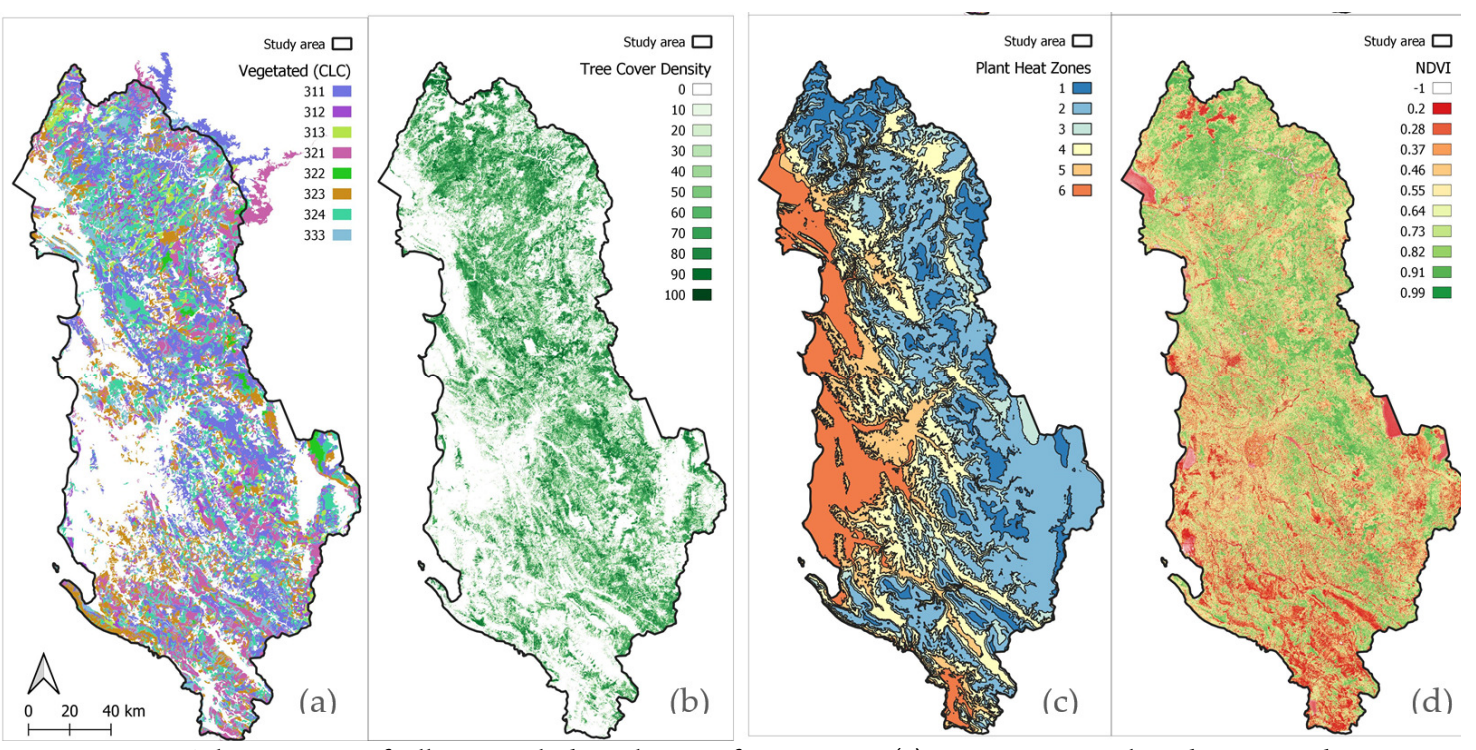

Figure 3. The territory of Albania including the new four criteria; (a) vegetation type based on CLC data of 2018, (b) tree cover density, (c) plant heat zones, and (d) NDVI

\section{CORINE Land Cover (CLC) and Tree Cover Density (TCD)}

Besides the utility of CLC data in providing information mainly about social criteria, at this stage it is used for classifying the vegetated surfaces under the 1st level category of Forests and semi natural areas by their fire capacity factors. As represented in Table 2 this relative value is derived from a ranking procedure of the 3 rd level classes of CLC according to a range between 1 (the lowest fire capacity) and 9 (the highest fire capacity). Accordingly, burned surfaces are assigned the lowest value considering the low amount of remaining fuel within an area that have recently experienced a wildfire event. On the other hand, the highest one is allocated to the broad-leaved forest surfaces considering the relatively high rates of flammability and the generous volume of fuel stock. Yet, the fire capacity factor can be further improved to enable a more reliable ranking among vegetated surface types by their flammability capacity.

On the other hand, we bring in tree cover density (TCD) as an extra criterion in calculating wildfire capacity. TCD data is derived from the Copernicus portal by EEA in raster format at a resolution of $100 \mathrm{~m}$. In this study we have used the data of 2015, which delivers information about the relative density values within a range of 0 and $100 \%$. In principle, the higher the TCD value the higher the fire capacity of a certain location within the vegetated surfaces. Both, the fuel type and the TCD are launched as crucial criteria in calculating the wildfire spreading capacity.

Table 2. The vegetation types as extracted from CLC data and their specific factor in relation to wildfire proneness

\begin{tabular}{|c|c|c|c|}
\hline $1^{\text {st }}$ level & $2^{\text {nd }}$ level & $3^{\text {rd }}$ level & Fire capacity factor \\
\hline 3 Forest and semi & 31 Forests & 311 Broad-leaved forest & 9 \\
\hline natural areas & & 312 Coniferous forest & 8 \\
\hline & & 313 Mixed forest & 3 \\
\hline & 32 Scrub and/or herbaceous & 321 Natural grasslands & 4 \\
\hline & vegetation associations & 322 Moors and heathland & 5 \\
\hline & & 323 Sclerophyllous vegetation & 6 \\
\hline & & 324 Transitional woodland-shrub & 2 \\
\hline & 33 Open spaces with little & 333 Sparsely vegetated areas & 1 \\
\hline
\end{tabular}




\section{Plant heat zone map of Albania}

The heat zones map was produced for the first time in 1997 by the American Horticultural Society (AHS) to help describe the impact that heat and drought play in plant survival (Cathey, 1997). It is a useful tool when choosing landscape plants in the regions of the country with hot summers. This map potentially has 12 zones based on the severity of summer heat (McMahon et al., 2011).

Teqja et al. (2018) developed a classification of plant heat zones for Albania based on AHS model and assessed the impact of climate change scenarios on distribution and trends of plant heat zones. Being based on the number of days exceeding $30^{\circ} \mathrm{C}$ the plant heat zones map is used as an indicator of plant heat stress. Heat stress and forest fires are often considered highly correlated hazards as extreme temperatures play a key role in both occurrences and extremely high temperatures are the common denominator for both heat stress and wildfires (Vitolo et al., 2019).

\section{Normalized difference vegetation index}

Normalized difference vegetation index (NDVI) data provides useful geospatial information about the land-surface properties. Basically, it is an indexing procedure based on the reflectance and absorbance capacity of vegetated surfaces within the red and near-infrared ranges of electromagnetic spectrum (EMS) (Chen et al., 2004). NDVI value provides information about the health of vegetation in reference to the absorption of photosynthetically active radiation (Sellers, 1985). The implications of NDVI value in reference to the wildfire regimes is already reported in literature (Leon et al., 2012). In principle, a healthy plant (high NDVI value) contains higher rates of water and moisture in its body and thus has lower wildfire spreading capacity by being more resilient to forest fire compared to unhealthy vegetation (low NDVI value).

In this study, the NVDI map is generated through raster calculator procedure utilizing the Sentinel 2 multi-spectral satellite images as acquired via the Semi-automatic classification plugin (SCP) in QGIS (Leroux et al., 2018; Alface et al., 2019). Accordingly, we have used band 4 (red) and band 8 (near infrared) for R RED and R NIR respectively as input in equation 2 . Both raster files are available at grain size of $10 \mathrm{~m}$.

NDVI is a ratio of the difference to the sum between the near-infrared and the red reflectance waveband:

$$
\mathrm{NDVI}=\left(\mathrm{R}_{\mathrm{NIR}}-\mathrm{R}_{\mathrm{RED}}\right) /\left(\mathrm{R}_{\mathrm{NIR}}+\mathrm{R}_{\mathrm{RED}}\right)
$$

where, R NIR represents the reflectance in the near-infrared waveband and R RED presents reflectance values in the red waveband.

\section{Results and Discussion}

\section{Inventory of relative risk for each criteria in Albanian territory}

The first results of this study are derived during the second stage of the workflow (see Table 1). The reference points that overlap with the vegetated surfaces are further counted for their values in reference to each criterion which is shortlisted as a factor having a certain impact on the wildfire spreading regimes in the territory. Referring to Table 3 , there are 15 criteria being considered during the calculation of WSCI values. They are grouped under four categories: environmental (E), fuel (F), physical (P), and social (S).

In total, there are 74,924 reference points that fall within the vegetated surfaces (CLC 2012), which served as reference points during the inventory stage. Considering that each point represents an area of 25 ha, in total there are 1,873,100 ha of vegetated surfaces within the territory of Albania. In other words, it consists of two thirds of the total national surface area $(18,731 \mathrm{~km} 2$ out of $28,748 \mathrm{~km} 2)$. During the inventory stage each point served as pivot location which have been loaded the specific measurements and raw values per each criterion. As a result, the attribute table of points layer consists of 15 attributes per each point.

Table 3 presents the inventory results of three selected records (out of 74,924). Namely, they are the points which represent the upper bound, lower bound and median values of WSCI indexing results as shown 
in the last row. Referring to the raw values in the first, third and the fifth columns, the range of values variety among criteria is obvious. For example, the range of values of criterion distance to urban centers (S1) is between 44377 and 39 meters. This range is relatively equivalent to other criteria which are based on distance values to certain physical elements in the territory. But they are much different in comparison to TCD (F3) and slope (P1) which range within the percentage gradient (0-100). Furthermore, narrower range of values is present in NDVI (F4) and wind speed (E4) values which do not exceed a max-min difference value of 2.7. Thus, as explained before a normalizing procedure is utilized and the respective normalized values of each raw measurements are included in the second, fourth and sixth columns of Table 3. As a result, the upper bound values are allocated a common top value of 1 , while the lower bound records are counted as 0 . And the median values are correspondingly assigned within the normalizing range between 0 and 1 .

Table 3. The inventory results including the upper bound, lower bound and median values of WSCI indexing results

\begin{tabular}{|c|c|c|c|c|c|c|c|c|}
\hline & Criterion & Unit & $\begin{array}{c}\text { Upper } \\
\text { bound }\end{array}$ & Norm & $\begin{array}{c}\text { Median } \\
\text { value }\end{array}$ & Norm & $\begin{array}{c}\text { Lower } \\
\text { bound }\end{array}$ & Norm \\
\hline E1 & Solar radiation & MJ m & 23390 & 1 & 22157 & 0.678 & 19561 & 0 \\
\hline E2 & Precipitation & $\mathrm{mm}$ & 80 & 1 & 49 & 0.466 & 22 & 0 \\
\hline E3 & Maximum temp. & $\circ \mathrm{C}$ & 30 & 1 & 24 & 0.642 & 12 & 0 \\
\hline E4 & Wind speed & $\mathrm{m} \mathrm{s}^{-1}$ & 3.6 & 1 & 1.5 & 0.222 & 0.9 & 0 \\
\hline F1 & Fuel type (CLC) & reclassify & 9 & 1 & 6 & 0.625 & 1 & 0 \\
\hline F2 & Vegetation Heat Zone & reclassify & 6 & 1 & 2 & 0.333 & 0 & 0 \\
\hline F3 & Tree Cover Density & $\%$ & 98 & 1 & 37 & 0.374 & 0 & 0 \\
\hline F4 & NDVI & ratio & 1 & 1 & 0.67 & 0.841 & -1 & 0 \\
\hline P1 & Slope & $\%$ & 89 & 1 & 18.5 & 0.209 & 0 & 0 \\
\hline P2 & Aspect & reclassify & 10 & 1 & 6 & 0.600 & 0 & 0 \\
\hline P3 & Altitude & $\mathrm{m}$ & 2671 & 1 & 891 & 0.334 & -3 & 0 \\
\hline P4 & Dist to water & $\mathrm{m}$ & 43791 & 1 & 7587 & 0.173 & 22 & 0 \\
\hline S1 & Dist. to Urban Cent & $\mathrm{m}$ & 44377 & 1 & 7147 & 0.160 & 39 & 0 \\
\hline S3 & Dist. to any road & $\mathrm{m}$ & 11791 & 1 & 1329 & 0.112 & 5 & 0 \\
\hline S4 & Dist. to main road & $\mathrm{m}$ & 21694 & 1 & 5093 & 0.234 & 11 & 0 \\
\hline Result & WSCI & & & 0.682 & & 0.390 & & 0.102 \\
\hline & WSCI normalized & & & 1 & & 0.496 & & 0 \\
\hline
\end{tabular}

Furthermore, besides the above-mentioned numerical results the inventory stage leads to visual outcomes via a series of maps. Figure 4 presents the inventory results per each criterion in a separate map within the study area. All measurements are normalized and reclassified into 10 classes in QGIS. The results are visually represented via red-yellow-blue gradient colour palette aiming to highlight the zones that are highly (red), moderately (yellow) and less (blue) affected by the specific criterion in reference to wildfire spreading capacity.

For example, Figure $4 \mathrm{~b}$ presents the relative impact of solar radiation on wildfire spreading capacity of vegetated areas within the study area. It has a certain visual similarity with the map of maximum temperature (Figure 4c) indicating a correlation between solar radiation and maximum temperature within a territory. On the other hand, maps of criteria that rely on distance to certain elements in the territory can indicate the areas that are remotely located from anthropogenic factors. For instance, distance to urban centers (Figure 4k), distance to main roads (Figure 4n) and distance to water sources (Figure 4j) indicate areas at risk due to the difficulty in wildfire suppression activity in remotely located zones in case of a fire. 


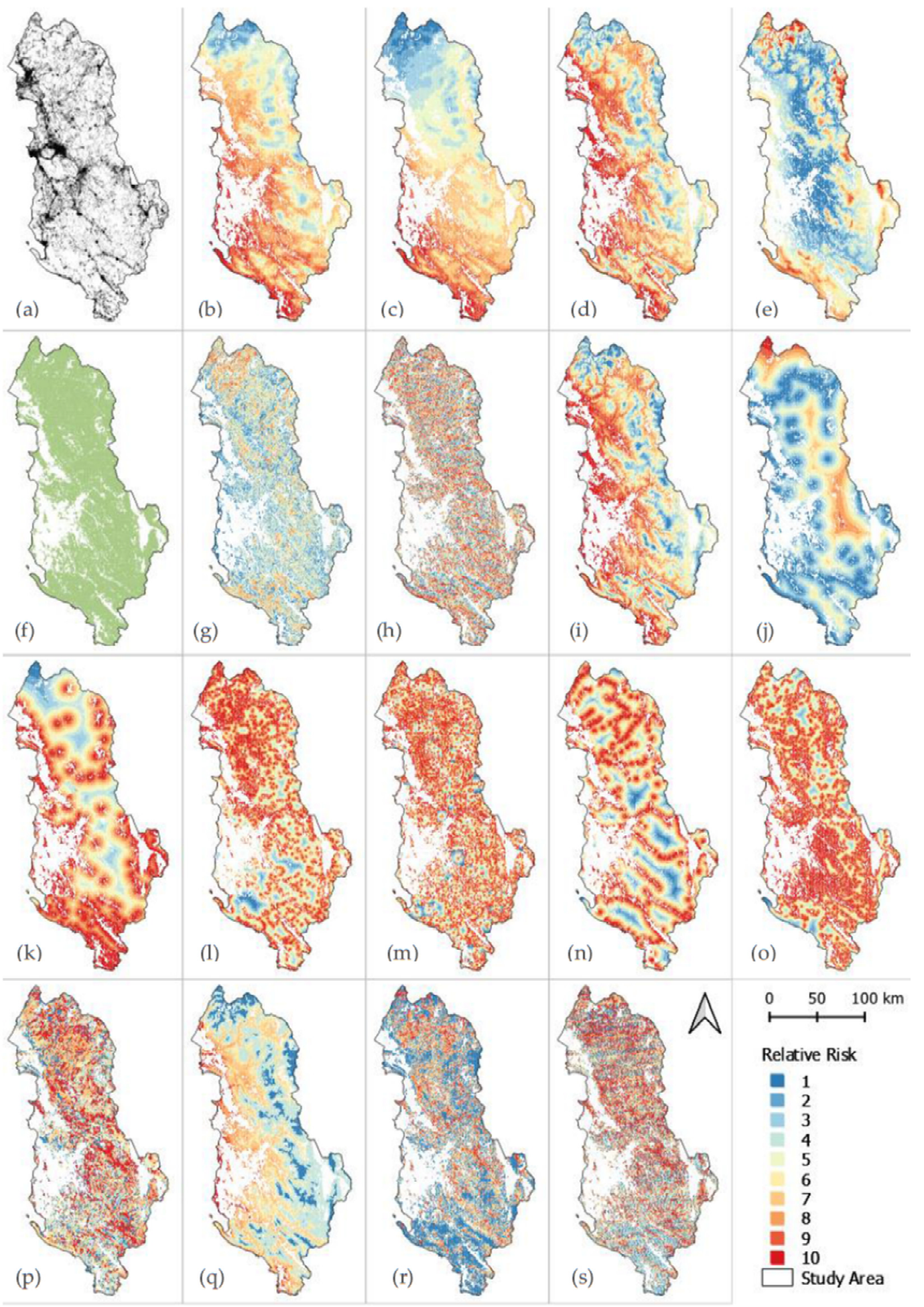

Figure 4. The territory of Albania including the transportation network (a) and natural vegetation (f), and the relative risk map for each criterion; solar radiation (b), precipitation (c), maximum temperature (d), wind speed $(\mathrm{e})$, slope $(\mathrm{g})$, aspect $(\mathrm{h})$, elevation $(\mathrm{i})$, distance to water $(\mathrm{j})$, dist. to urban centres $(\mathrm{k})$, dist. to settlements (l), dist. to any road $(\mathrm{m})$, dist. to main road $(\mathrm{n})$, dist. to agriculture (o), vegetation type-CLC $(\mathrm{p})$, heat zones $(\mathrm{q})$, tree cover density $(\mathrm{r})$, NDVI $(\mathrm{s})$ 


\section{Calculation and mapping of WSCI values for the vegetated surfaces in Albania}

At the final empirical stage, the normalized inventory values per each criterion $(C \mathrm{j})$ are the first set of values to be included in the process of WSCI calculation. While the second set consists of the weighted impact factor of each criterion. This relies on the fact that not all shortlisted criteria have the same impact level on wildfire spreading regimes. As previously stated, we have utilized AHP pairwise comparison method for assigning a weighted value to each criterion, aiming to normalize their relative impact on the final WSCI value.

As shown in Table 4, the weights are calculated in two steps. First, the AHP method is applied for weighting among four main categories of the criteria (Social, Environmental, Physical, and Fuel). These values are presented in the second values' column of the following table (IF category). Then, the individual criteria are weighted among each other within their specific category, the results of which are included in the first values' column (IF within category).

The very final weighted values $(\beta j)$ per each criterion are included in the last column as a product of the former two. According to the final AHP weighting, the criteria that results to have the highest impact in WSCI values are tree cover density (F3), NDVI (F4), and wind speed (E4), marking almost $60 \%$ of the total weight. On the other hand, the criteria that affect the least are altitude (P3) and distance to any road (S3), consisting $1.2 \%$ of the total shared wildfire spreading capacity.

Table 4. Multi-criteria used in WSCI index calculation, including their respective relevancy and their impact factor within and among categories $(\beta \mathrm{j})$

\begin{tabular}{|c|c|c|c|c|c|c|c|}
\hline Category & & & Criteria & 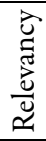 & 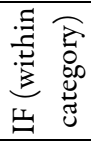 & 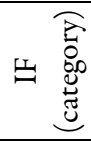 & $\underset{\underbrace{}}{\stackrel{\hat{\sigma}}{\omega}}$ \\
\hline \multirow{3}{*}{ Social } & 1 & S1 & Dist. to Urban Cent & + & 0.243 & 0.071 & 0.017 \\
\hline & 2 & S3 & Dist. to any road & + & 0.088 & 0.071 & 0.006 \\
\hline & 3 & $S 4$ & Dist. to main road & + & 0.669 & 0.071 & 0.047 \\
\hline \multirow{4}{*}{ Environmental } & 4 & E1 & Solar radiation & + & 0.046 & 0.235 & 0.011 \\
\hline & 5 & E2 & Precipitation & - & 0.203 & 0.235 & 0.048 \\
\hline & 6 & E3 & Maximum temp. & + & 0.094 & 0.235 & 0.022 \\
\hline & 7 & E4 & Wind speed & + & 0.657 & 0.235 & 0.155 \\
\hline \multirow{4}{*}{ Physical } & 8 & P1 & Slope & + & 0.271 & 0.122 & 0.033 \\
\hline & 9 & $\mathrm{P} 2$ & Aspect & + & 0.110 & 0.122 & 0.013 \\
\hline & 10 & P3 & Altitude & - & 0.045 & 0.122 & 0.006 \\
\hline & 11 & $\mathrm{P} 4$ & Dist. to water & + & 0.573 & 0.122 & 0.070 \\
\hline \multirow{5}{*}{ Fuel } & 12 & $\mathrm{~F} 1$ & Fuel type (CLC) & + & 0.122 & 0.571 & 0.070 \\
\hline & 13 & $\mathrm{~F} 2$ & Vegetation Heat Zone & + & 0.057 & 0.571 & 0.033 \\
\hline & 14 & F3 & Tree Cover Density & + & 0.523 & 0.571 & 0.299 \\
\hline & 15 & $\mathrm{~F} 4$ & NDVI & - & 0.298 & 0.571 & 0.170 \\
\hline & & & & & & 1.00 & 1.00 \\
\hline
\end{tabular}

Another detail here is the relevancy of each criterion in reference to wildfire spreading behaviour. Some criteria have a direct relation with the WSCI value. For example, the larger the distance to urban centres (S1), the distance to main roads (S3), and the distance to water sources (P4) the higher the chances for fire spread, considering the suppression accessibility. Similarly, the high values of solar radiation (E1), maximum temperature (E3), wind speed (E4), slope (P1), and aspect (P2) increases the chances for a wildfire to spread further.

While, other criteria are reversely related with wildfire spread. For instance, the higher precipitation (E2) and altitude (P3) values the lower the spreading capacities of a wildfire. WSCI equation consists of the sum of the products between the normalized inventory measurement $(\mathrm{Cj})$ and the weighted impact factor $(\beta \mathrm{j})$ per each criterion: 


$$
W S C I=\sum_{j=1}^{m} \beta_{j} \mathbb{C}_{j}
$$

Where, $\beta j$ is the weighted value of criterion $j$, and $C j$ is the normalized inventory value of criterion $j$

As a result, each reference point has been assigned a new value of WSCI index in the attributes table. The equation 3 is performed as an expression via field calculation in QGIS. The results of the maximum, median and the minimum WSCI values are already presented in Table 3. Besides the absolute WSCI values, we performed a final normalizing procedure to reclassify the index values into a range of values between 0 and 1. This is crucial especially in representing the results in visual maps through which the relative risk distribution becomes more evident. The results of WSCI calculation are shown in Figure 5.

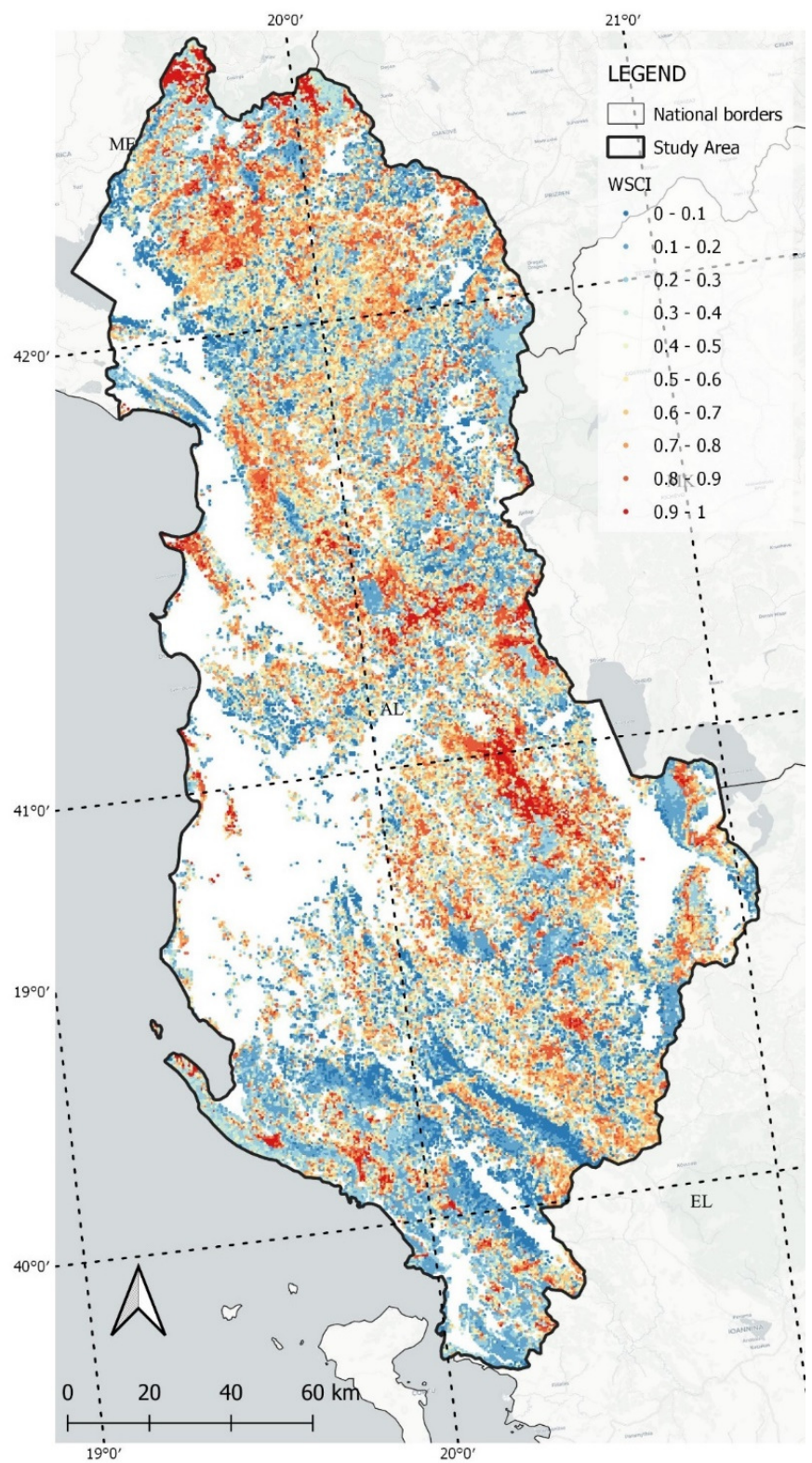

Figure 5. The normalized WSCI indexing results for Albanian territory 


\section{Discussion on validity of the results and further improvements}

At this stage of validation, the records of some reference points locations are omitted to increase the thoughtfulness of the results. Through a detailed investigation of 74,924 records, it was realized that some point locations have "NULL" or " 0 " value of certain criteria. For example, there are 392 points that have been loaded a solar radiation (E1) value of "0". Considering that the lower bound of E1 values is $19561 \mathrm{MJ} \mathrm{m}^{-2}$ it implies for an incorrect mapping due to the lack of raster coverage at the specific point location. Similarly, there are 7649 -point locations in total which have inconsistent records at least in one of the criteria. The final discussion on validation is based on the results of the remaining 67275 reference point locations.

The validation process could be much reliable if supported by historical geospatial data about the occurrence and spreading regimes of wildfire within the study area (Verde and Zêzere, 2010). But as it was earlier stated such geospatial data are missing in Albania. Thus, the method presented in this paper aims to provide a reliable tool for wildfire spreading capacity estimation in absence of historical data. Accordingly, the higher the WSCI values of points that represents burned surfaces, the higher the validity of the method.

In this study due to the lack of historical data at local scale, we have utilized the CLC data in localizing the reference points that fall within burned areas as presented in Figure 6. Considering that CLC data has a very raw grain size, it is unable to provide information about fires smaller than $25 \mathrm{ha}$, and not to mention the ignition cases with no significant spread. Consequently, the reliability level remains at landscape level.

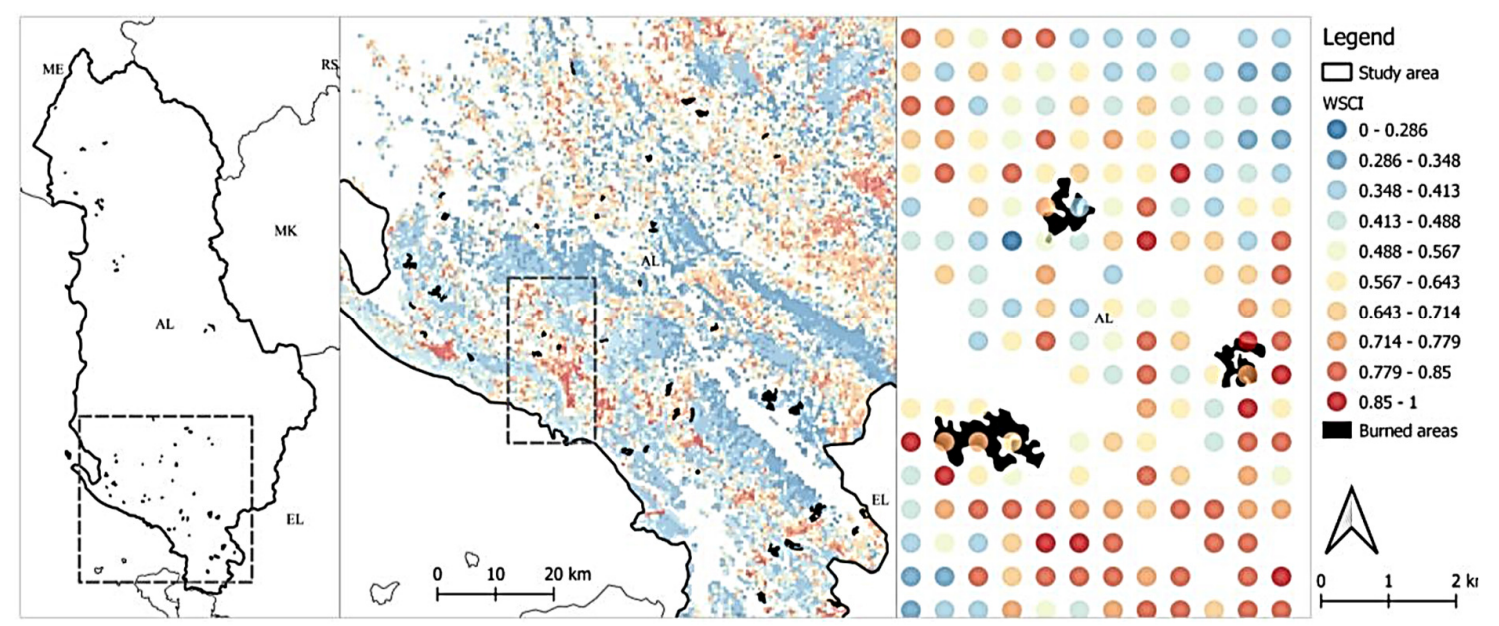

Figure 6. The spatial relationship of burned areas (CLC of 2018) and the indexed reference points according to WSCI values

The scatter plot of WSCI and wildfire ignition probability index (WIPI) values presented in Figure 7 highlights the values of points that overlap with the burned surfaces in comparison with the other records. According to the scatter plot a considerable amount of highlighted points are located at relatively higher values. On the other hand, the remaining point locations that have relatively high WSCI and WIPI values imply for highly vulnerable vegetated areas to wildfire risk. Such locations can be further tested if they represent areas of significant territorial importance at national and regional level, such as natural reserves or protected areas. Furthermore, the distance of these points with the human settlement and social activities is crucial in terms of wildfire risk reduction at local levels. 


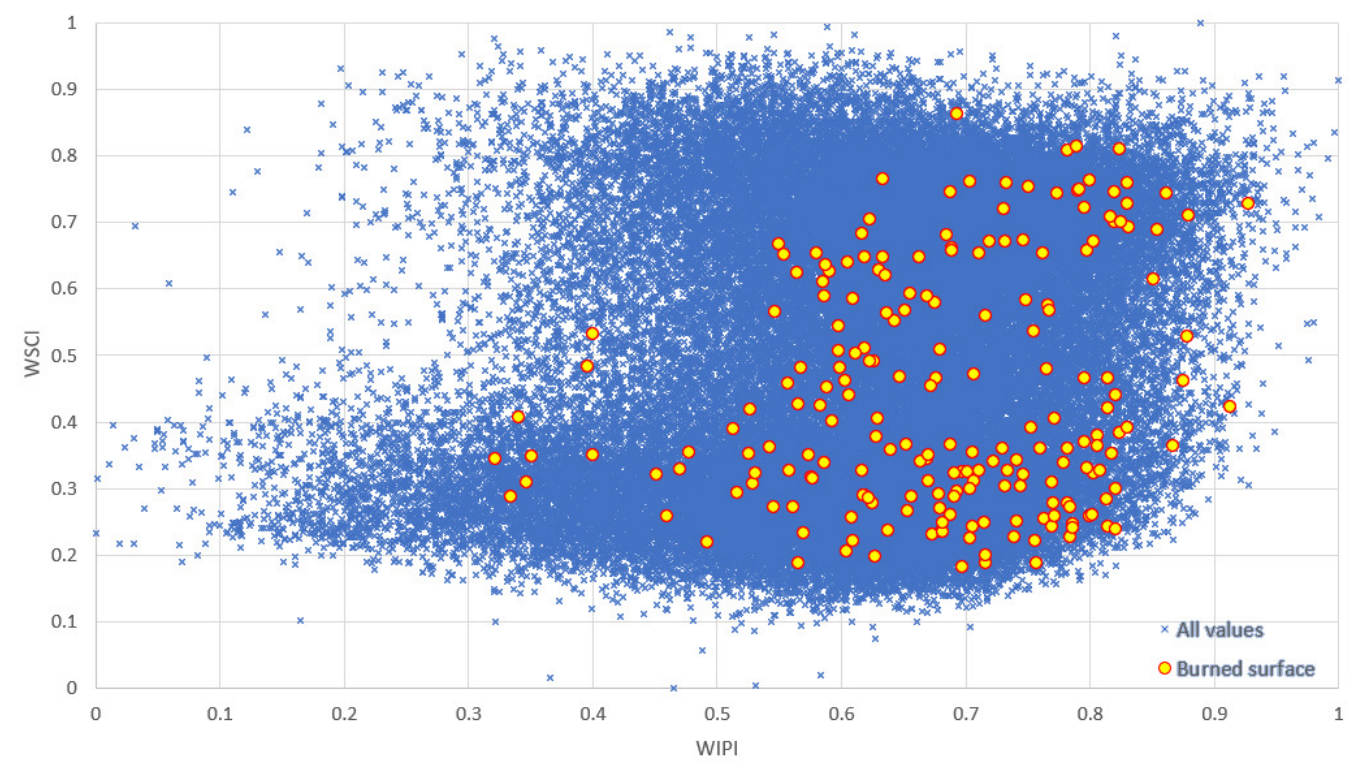

Figure 7. Scatter plot of WIPI to WSCI values where the values of points on burned areas are highlighted in red circles

\section{Conclusions}

This study presented a rapid and cost-free method for classifying the vegetated surfaces of a territory by their wildfire spreading capacities. The method follows a multi-criteria approach, considering the wildfire as a phenomenon of an intermingled character, implicating a variety of factors being present in the landscape. QGIS software results a reliable platform for constructing the procedural steps of the analytical workflow. Furthermore, it provides enough ground for automating the process into a model to provide easy reproduction to other study areas.

Even though, the results show that in Albania the majority of vegetated surfaces that are relatively holding higher wildfire spread capacities are at remote locations in reference to major urbanized areas, there still exists a high risk of societal losses in small settlements and villages where the wildfire suppression capacities are at minimum. The wildfire spread capacity maps provides useful spatial information to inform disaster risk management and fire safety agendas in national and regional scale. According to the results presented here, the WSCI values of locations within the already burned surfaces are relatively high compared with other locations within the study area. Yet, a validation method relying on geospatial historical data about the wildfire regimes in the territory may increase the validation reliability.

The proposed method is primarily useful for study areas and regions that lack historical data about the wildfire regimes, which is a frequent condition in under-developed and developing countries. This is more crucial in regions like western Balkans within the Mediterranean zone, in which the lack of historical data and the increasing wildfire risk are significant conditions. As it is previously reported, over 220,000 hectares of forest were burned in the years 2007 and 2012 alone within the western Balkan region, which includes parts of Southern and Eastern Europe including Albania. According to the same report in this region, the current legal, policy, and institutional frameworks contain necessary directives for managing wildfires (Nemeth 2015). But, in practice the strengthening of prevention measures remains a challenge. The method presented in this study can be considered a contribution to the pre-occurrence phase of the wildfire management processes. 


\section{Authors' Contributions}

Conceptualization: AH; Methodology: AH; Software: AH; Calculations: AH; Literature: AH and ZT; Data curation, AH; Writing-original draft preparation: $\mathrm{AH}$ and $\mathrm{ZT}$; Writing-review and editing: $\mathrm{AH}$ and ZT; Visualization: $\mathrm{AH}$; funding acquisition: $\mathrm{AH}$ and $\mathrm{ZT}$.

Both authors read and approved the final manuscript.

\section{Acknowledgements}

The research is inspired by the synergy generated within the project FIRElinks (CA18135 - Fire in the Earth System: Science \& Society). Furthermore, the original method has been motivated by the objectives of the Erasmus+ capacity building project, "Knowledge for Resilient society - K-FORCE" in which Epoka University has been a member. This research received no specific grant from any funding agency in the public, commercial, or not-for-profit sectors.

The hereby work was accepted and presented at the GEA (Geo Eco-Eco Agro) International Conference 28 May 2020, Podgorica, Montenegro, and it has been published as abstract in "Book of Abstracts" (http://www.gea.ucg.ac.me/page.php?id=64).

\section{Conflict of Interests}

The authors declare that there are no conflicts of interest related to this article.

\section{References}

Alface AB, Pereira SB, Filgueiras R, Cunha FF (2019). Sugarcane spatial-temporal monitoring and crop coefficient estimation through NDVI. Revista Brasileira de Engenharia Agrícola e Ambiental 23(5):330-335. https://doi.org/10.1590/1807-1929/agriambi.v23n5p330-335

Büttner G (2014). CORINE Land Cover and Land Cover Change Products. In: Manakos I, Braun M (Eds). Land Use and Land Cover Mapping in Europe: Practices \& Trends. Springer, Dordrecht, Netherlands pp 55-74.

Cardille JA, Ventura SJ, Turner MG (2001). Environmental and social factors influencing wildfires in the Upper Midwest, United States. Ecological Applications 11(1):111-127. https://doi.org/10.1890/10510761(2001)011[0111:easfiw]2.0.co;2

Chapin FS, Trainor SF, Huntington O, Lovecraft AL, Zavaleta E, Natcher DC, Fresco N (2008). Increasing wildfire in Alaska's boreal forest: pathways to potential solutions of a wicked problem. BioScience 58(6):531-540. https://doi.org/10.1641/b580609

Cathey HM (1997). Announcing the AHS plant heat-zone map. American Gardener 76(5):30-37.

Chen J, Jönsson P, Tamura M, Gu Z, Matsushita B, Eklundh L (2004). A simple method for reconstructing a high-quality NDVI time-series data set based on the Savitzky-Golay filter. Remote sensing of Environment 91(3-4):332-344. https://doi.org/10.1016/j.rse.2004.03.014

Fick SE, Hijmans RJ (2017). WorldClim 2: new $1 \mathrm{~km}$ spatial resolution climate surfaces for global land areas. International Journal of Climatology 37(12):4302-4315. https://doi.org/10.1002/joc.5086

Fischer AP, Spies TA, Steelman TA, Moseley C, Johnson BR, Bailey JD, Kline JD (2016). Wildfire risk as a socioecological pathology. Frontiers in Ecology and the Environment 14(5):276-284. https://doi.org/10.1002/fee.1283

Goepel KD (2018). Implementation of an online software tool for the analytic hierarchy process (AHP-OS). International Journal of the Analytic Hierarchy Process 10(3):469-487. https://doi.org/10.13033/ijahp.v10i3.590 
He T, Belcher CM, Lamont BB, Lim SL (2016). A 350-million-year legacy of fire adaptation among conifers. Journal of Ecology 104(2):352-363. https://doi.org/10.1111/1365-2745.12513

Hysa A, Başkaya FAT (2019). A GIS based method for indexing the broad-leaved forest surfaces by their wildfire ignition probability and wildfire spreading capacity. Modeling Earth Systems and Environment 5(1):71-84. https://doi.org/10.1007/s40808-018-0519-9

Hysa A (2019). Identifying the forest surfaces prone to fire ignition and wildfire spread in metropolitan areas; a comparative case from western Balkans. Proceedings 30(1):1. https://doi.org/10.3390/proceedings2019030001

Hysa A, Zeka E, Dervishi S (2017). Multi-criteria Inventory of Burned Areas in Landscape Scale; Case of Albania. KFORCE first Symposium. Novi Sad, Serbia pp 86-100.

Jaho S, Mici A (1988). Climate atlas of the PSR of Albania. Akademia e Shkencave e RPS tëShqipërisë, Instituti Hidrometeorologjik. Retrieved 2020 April 29 from https://trove.nla.gov.au/work/6476979

Jain A, Nandakumar K, Ross A (2005). Score normalization in multimodal biometric systems. Pattern recognition 38(12):2270-2285. https://doi.org/10.1016/j.patcog.2005.01.012

Kulig J, Botey AP (2016). Facing a wildfire: What did we learn about individual and community resilience?. Natural Hazards 82(3):1919-1929. https://doi.org/10.1007/s11069-016-2277-1

Leon JRR, Van Leeuwen WJ, Casady GM (2012). Using MODIS-NDVI for the modeling of post-wildfire vegetation response as a function of environmental conditions and pre-fire restoration treatments. Remote sensing 4(3):598-621. https://doi.org/10.3390/rs4030598

Leroux L, Congedo L, Bellón B, Gaetano R, Bégué A (2018). Land cover mapping using Sentinel-2 images and the semiautomatic classification plugin: A Northern Burkina Faso case study. In: Baghdadi N, Mallet C, Zribi M (Ed). QGIS and Applications in Agriculture and Forest. ISTE Ltd and John Wiley \& Sons, Inc. pp 119-151. https://doi.org/10.1002/9781119457107.ch4

Levin N, Tessler N, Smith A, McAlpine C (2016). The human and physical determinants of wildfires and burnt areas in Israel. Environmental Management 58(3):549-562. http://dx.doi.org/10.1007/s00267-016-0725-Z

Liu Y, Stanturf J, Goodrick S (2010). Trends in global wildfire potential in a changing climate. Forest Ecology and Management 259(4):685-697. https://doi.org/10.1016/j.foreco.2009.09.002

McMahon ME, Kofranek AM, Rubatzky VE (2011). Plant Science: Growth, Development, and Utilization of Cultivated Plants. Prentice Hall $\left(5^{\text {th }}\right.$ ed), Boston.

Moriondo M, Good P, Durao R, Bindi M, Giannakopoulos C, Corte-Real J (2006). Potential impact of climate change on fire risk in the Mediterranean area. Climate Research 31(1):85-95. https://doi.org/10.3354/cr031085

Mullaj A, Hoda P, Shuka L, Miho A, Bego F, Qirjo M (2017). About green practices for Albania. Albanian Journal of Agricultural Sciences 31-50. http://ajas.inovacion.al/about-green-practices-for-albania/

Nemeth A (2015). Forest Fires in South Eastern Europe. Regional Environmental Center for Central and Eastern Europe. Retrieved 2020 April 30 from http://www.rec.org/publication.php?id=505

Scott AC (2000). The Pre-Quaternary history of fire. Palaeogeography, Palaeoclimatology, Palaeoecology 164(1-4):281329. https://doi.org/10.1016/s0031-0182(00)00192-9

Sellers PJ (1985). Canopy reflectance, photosynthesis and transpiration. International Journal of Remote Sensing 6(8):1335-1372. https://doi.org/10.1080/01431168508948283

Teqja Z, Kopali A, Libohova Z, Owens PR (2017). A study of the impacts of climate change scenarios on the plant hardiness zones of Albania. Journal of Applied Meteorology and Climatology 56(3):615-631. https://doi.org/10.1175/jamc-d-16-0108.1

Teqja Z, Libohova Z, Owens P, Kopali A (2018). The impact of climate change scenarios on plant heat zones of Albania. Albanian Journal of Agricultural Sciences 56(3):10-21.

Turco M, Llasat MC, von Hardenberg J, Provenzale A (2014). Climate change impacts on wildfires in a Mediterranean environment. Climatic Change 125(3-4):369-380. https://doi.org/10.1007/s10584-014-1183-3

Verde JC, Zêzere JL (2010). Assessment and validation of wildfire susceptibility and hazard in Portugal. Natural Hazards \& Earth System Sciences 10(3):485-497. https://doi.org/10.5194/nhess-10-485-2010

Vitolo C, Di Napoli C, Di Giuseppe F, Cloke HL, Pappenberger F (2019). Mapping combined wildfire and heat stress hazards to improve evidence-based decision making. Environment International 127:21-34. https://doi.org/10.1016/j.envint.2019.03.008

Zdruli P (2005). Soil survey in Albania. Soil Resources of Europe, European Soil Bureau. Retrieved 2020 April 29 from https://www.researchgate.net/publication/240637783_Soil_Survey_in_Albania 
Hysa A and Teqja Z (2020). Not Bot Horti Agrobo 48(3):1667-1682

OPEN ACCESS

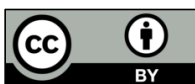

The journal offers free, immediate, and unrestricted access to peer-reviewed research and scholarly work. Users are allowed to read, download, copy, distribute, print, search, or link to the full texts of the articles, or use them for any other lawful purpose, without asking prior permission from the publisher or the author.

License - Articles published in Notulae Botanicae Horti Agrobotanici Cluj-Napoca are Open-Access, distributed under the terms and conditions of the Creative Commons Attribution (CC BY 4.0) License.

(c) Articles by the authors; UASVM, Cluj-Napoca, Romania. The journal allows the author(s) to hold the copyright/to retain publishing rights without restriction. 